Article

\title{
Effect of Thermal and Oxidative Aging on Asphalt Binders Rheology and Chemical Composition
}

\author{
Ingrid Gabrielle do Nascimento Camargo ${ }^{1, *}$, Bernhard Hofko ${ }^{1} \mathbb{C}$, Johannes Mirwald ${ }^{2}$ \\ and Hinrich Grothe 2 (D) \\ 1 Institute of Transportation, TU Wien, Gusshausstrasse 28/E230-3, 1040 Vienna, Austria; \\ bernhard.hofko@tuwien.ac.at \\ 2 Institute of Materials Chemistry, TU Wien, Getreidemarkt 9/E-165-01-5, 1060 Vienna, Austria; \\ johannes.mirwald@tuwien.ac.at (J.M.); hinrich.grothe@tuwien.ac.at (H.G.) \\ * Correspondence: ingrid.camargo@tuwien.ac.at
}

Received: 27 August 2020; Accepted: 29 September 2020; Published: 6 October 2020

\begin{abstract}
Aging of asphalt binders is one of the main causes of its hardening, which negatively affects the cracking and fatigue resistance of asphalt binders. Understanding asphalt aging is crucial to improve the durability of asphalt pavements. In this regard, this study aims at understanding and differentiating the effect of temperature and oxygen uptake on the aging mechanisms of unmodified asphalt binders. For that, four laboratory aging procedures were employed. The two standardized procedures, rolling thin-film oven test (RTFOT) and pressure aging vessel (PAV), were considered to simulate the short-term and long-term aging of the asphalt binders, respectively. In addition, two thin-film aging test procedures, the nitrogen atmosphere oven aging test (NAAT) and ambient atmosphere oven aging test (OAAT) were employed to assess the effect of thermal and oxidative aging on unmodified asphalt binder properties. The NAAT procedure is based on the principle that the inert gas minimizes the oxidative aging. The rheological and chemical characterization showed that the high temperatures considered during the NAAT procedure did not change the properties of the unmodified asphalt binders. Therefore, it can be hypothesized that no significant thermal and oxidative aging was observed during NAAT aging procedure for the considered binders and that oxidative aging is the main cause for the hardening.
\end{abstract}

Keywords: thermal aging; oxidative aging; asphalt binders; rheology; chemical composition

\section{Introduction}

Increased awareness of the environmental impacts generated during the service life of road infrastructures supports the incorporation of ecological concepts during planning, design, construction, operation, management, and recycling of pavements. To promote sustainability, road infrastructure should be cost effective, address environmental concerns, and contemplate social concerns without compromising pavement performance [1-3].

The enhancement of asphalt pavements durability is a promising way to improve its overall sustainability. The increase in the lifespan of pavements may result in the reduction in the number of pavement maintenance intervention, the use of nonrenewable materials, energy consumption, emissions of greenhouse gases, costs, and waste generation [4,5].

Among several factors, such as pavement design, aggregates characteristics, asphalt binder chemical composition, construction practices, traffic and environment conditions, aging is one of the main factors that impacts the durability of asphalt pavements. Since aging leads to an increase in asphalt binder stiffness and brittleness, it contributes to the premature development of fatigue and thermal cracking $[6,7]$. Therefore, to increase the durability of asphalt pavements, it is necessary 
to understand the mechanisms and parameters that lead the pavement to deteriorate earlier than designed. Among these mechanisms stands out the hardening of the asphalt binder during its aging since it affects negatively the cracking resistance of asphalt binders.

The hardening undergone by the asphalt binder can be reversible or irreversible. The reversible hardening (physical aging or steric aging) is caused by the reorganization of asphalt binder molecules and/or wax crystallization, which can be reversed by the warming up of the asphalt binder [8-11]. The irreversible aging (chemical aging) is caused by different processes such as oxidation, polymerization, evaporation of light components, and exudation of oil components from asphalt binder into a mineral aggregate [11,12].

The kinetics of asphalt binder oxidation is an important instrument used to understand the chemical changes during oxidative aging which results in asphalt binder hardening. The study of Petersen and Harnsberger (1998) [13] showed that asphalt oxidation is a dual mechanism, the first period is characterized by a fast reaction period and then followed by the second period related to slower reactions. In the fast reaction (spurt) period, oxygen reacts with perhydroaromatics to form hydroperoxide that can either react with sulfides to form sulfoxides or/and decompose into free radicals and/or undergo aromatization. During the slower reaction period, the reactions occur at a constant rate, resulting mainly in the formation of ketones and sulfoxide functional groups. The ketones formation during the asphalt binder oxidation is correlated to the increase in asphaltenes and its viscosity $[13,14]$. The concentration of the products formed (mainly ketones and sulfoxides) is dependent on the oxygen concentration, temperature, and sulfur content [15].

The aging of asphalt pavements occurs throughout its service life. During the production of asphalt mixtures, the binder undergoes aging due to the high temperatures utilized in the mixing process. The aging caused by the production of asphalt mixture together with the degradation of asphalt binders during temporary construction, which is related to storage, transport, and laying, is commonly referred to as short-term aging (STA). The main results of STA are the loss of volatiles and fast oxidation of asphalt binders $[6,16]$. Consequently, long-term aging (LTA) occurs over the road service life due to the interactions of the pavement with reactive oxygen species (ROS) in the atmosphere, moisture, temperature, and UV radiation. The LTA is mainly connected to the incorporation of oxygen, which leads to the formation of several functional groups, increasing the overall polarity of the material [17].

The STA and LTA are simulated by standardized aging procedures commonly referred to as rolling thin-film oven test (RTFOT) and pressure aging vessel (PAV), respectively. These laboratory aging procedures utilize high temperature and/or pressure to significantly increase oxidation rate and hence reduce the time needed to age the asphalt binder to a similar level as in the field [6,16,18]. Moreover, the setup of the conventional aging procedures allows for simulating the thermal-oxidative aging of the asphalt binder during the service life of the pavement.

Given the lack of studies that examine the key impact of the thermal and oxidative aging on the hardening of asphalt binders, this study aims at understanding and distinguishing the effect of thermal and oxidative aging on unmodified asphalt binders using alternative methods of aging. In the context of this paper, thermal aging refers to all mechanisms of aging except for extrinsic oxidation (e.g., volatilization).

The nitrogen atmosphere oven aging test (NAAT) consists of subjecting a thin film of unmodified asphalt binders to heat $\left(163^{\circ} \mathrm{C}\right)$ under an inert gas for $4 \mathrm{~h}$. The inert atmosphere minimized oxidation caused by the presence of oxygen, which allows a more accurate evaluation of the thermal effects on unmodified asphalt binders. Moreover, the rheological and chemical characterization of the asphalt binders at unaged and at different aging conditions indicated that oxidative aging is the main responsible factor of the hardening of the unmodified asphalt binders. 


\section{Materials and Methods}

\subsection{Materials}

Two unmodified 70/100 penetration graded asphalt binders, which are commonly used in Central and Western Europe for road pavements were used in this study. These asphalt binders were from different suppliers and were named " $\mathrm{A}$ " and " $\mathrm{B}$," respectively. Their physical properties are shown in Table 1:

Table 1. Characteristics of the unmodified asphalt binders.

\begin{tabular}{ccccc}
\hline Binder Properties & Units & Binder A & Binder B & Specifications \\
\hline Performance grade $(\mathrm{PG})$ & - & $64-22$ & $64-28$ & - \\
Penetration $\left(25^{\circ} \mathrm{C}\right)$ & $0.1 \mathrm{~mm}$ & 79 & 88 & EN 1426 [19] \\
Softening point & ${ }^{\circ} \mathrm{C}$ & 47.2 & 45.0 & EN 1427 [20] \\
Density $\left(15^{\circ} \mathrm{C}\right)$ & $\mathrm{g} / \mathrm{cm}^{3}$ & 1.02 & 1.02 & - \\
\hline
\end{tabular}

\subsection{Aging Procedures}

In this study, four distinct laboratory aging procedures were considered to understand the effect of the temperature and oxidation on two different asphalt binders (A and B). The short-term and long-term aging were simulated by standardized procedures, known as rolling thin-film oven test (RTFOT), EN 12607-1 [21] and pressure ageing vessel (PAV), EN 14769 [22], respectively. Additionally, two thin-film aging test procedures were proposed to investigate the effect of thermal and oxidative aging on asphalt binders, in this study. The proposed procedures were called as nitrogen atmosphere oven aging test (NAAT) and ambient atmosphere oven aging test (OAAT).

To prepare the thin-film asphalt binder samples which were considered in both procedures (NAAT and OAAT), an amount of $28.8 \pm 0.5 \mathrm{~g}$ of melted unaged asphalt binder was poured into stainless steel pan with a diameter of $140 \pm 2 \mathrm{~mm}$. Immediately, after pouring the asphalt binder, the pan was tilted and then placed on a level platform to ensure a uniform film thickness of about $1.90 \mathrm{~mm}$ (Figure 1a).

After the asphalt binder thin-film samples had cooled down to room temperature, they were placed into pan holders (Figure 1b). Two sets of pan holders loaded with five binder samples each were prepared. One set was used on NAAT and the other on OAAT aging procedure.

In the case of NAAT procedure, the pan holder set was placed into a glass vacuum desiccator. Subsequently, the desiccator was closed by sliding motion between the desiccator and its cap. The closure interface between the cap and the desiccator was coated with grease to ensure sufficient sealing. Consecutively, nitrogen was purged through the hole on the top of the cap for $10 \mathrm{~min}$ (Figure 1c), and after that, the hole was closed with a glass stopcock to ensure that nitrogen remained in the desiccator (Figure 1d).

The desiccator filled with nitrogen (NAAT) and the other set of pan holders (OAAT) were placed into a universal heating oven (Memmert, natural convection mode) at $163^{\circ} \mathrm{C}$ for $4 \mathrm{~h}$. The temperature in the desiccator was monitored in a preliminary test to ensure that both samples experience the same thermal loading. After the NAAT and OAAT aging procedures were finished, the desiccator and the set pan holder sample were removed from the oven. As for the NAAT procedure, it was necessary to open the stopcock to vent the nitrogen from the desiccator before collecting the binder. The asphalt binders obtained in each one of the aging procedures were collected in metallic cans to be used for further rheological and chemical characterization.

It should be highlighted that the NAAT and OAAT aging procedures have been reproduced twice, for each binder (A and B), to assure the reliability of both aging methods. Fourier-transform infrared spectroscopy technique was used to evaluate the repeatability of NAAT and OAAT aging procedures. The comparison of the carbonyl and sulfoxide indices between the results of a given aged binder showed that both proposed aging procedures demonstrated good repeatability. 
The suffixes Unaged, NAAT, OAAT, RTFOT, and RTFOT + PAV were added to each binder named "A" or "B" to specify the binder aging state (Table 2).

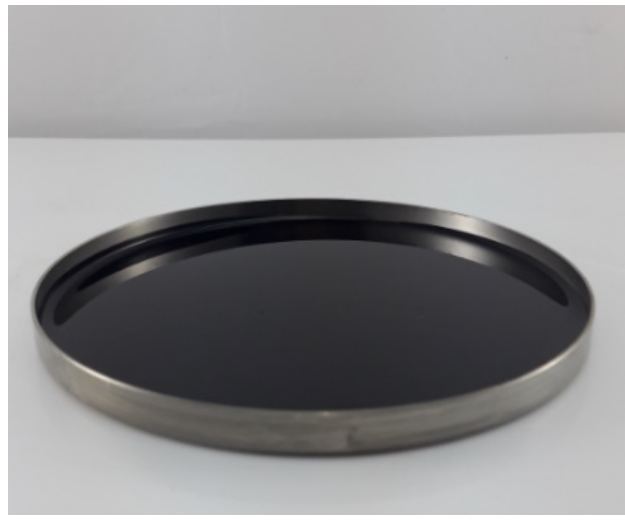

(a)

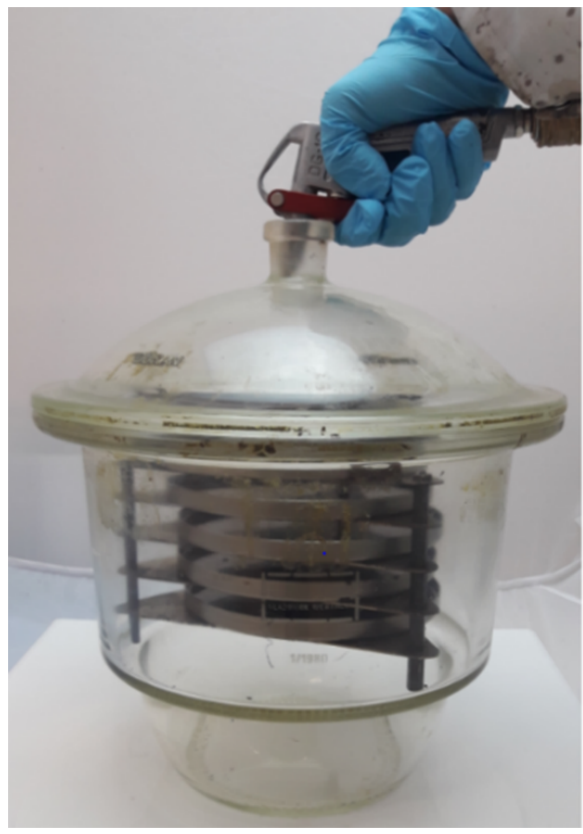

(c)

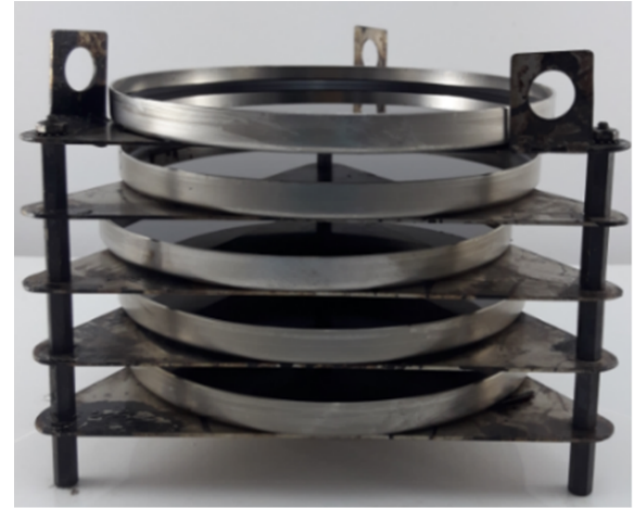

(b)

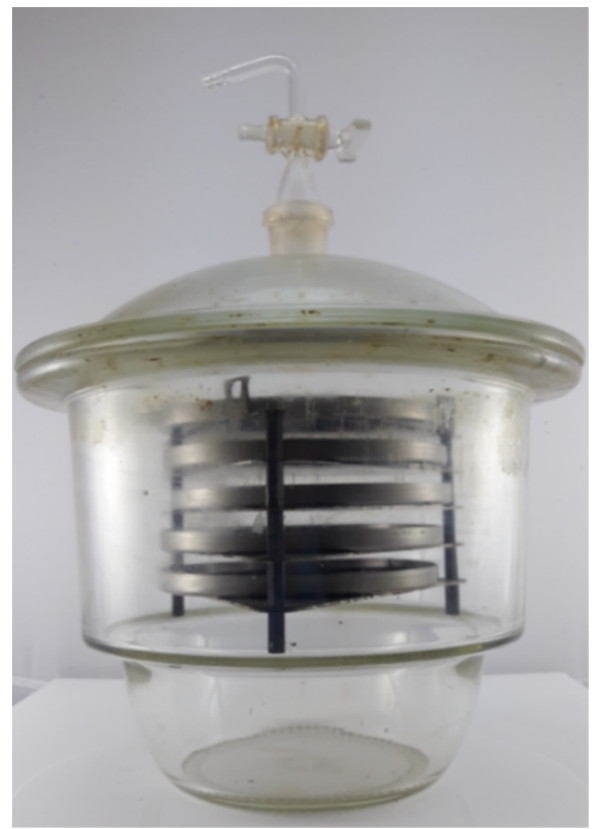

(d)

Figure 1. Sample preparation and nitrogen atmosphere oven aging test (NAAT) procedure: (a) example of thin-film sample considered in NAAT and ambient atmosphere oven aging test (OAAT) aging procedures, (b) set of holder pan filled with thin-film asphalt binder samples, (c) the desiccator is filled with nitrogen gas, and (d) desiccator filled with nitrogen.

Table 2. Codification used for each asphalt binder considered.

\begin{tabular}{ccc}
\hline Asphalt Binder Aging State & Binder A & Binder B \\
\hline Unaged binder & A_Unaged & B_Unaged \\
NAAT aged binder & A_NAAT & B_NAAT \\
OAAT aged binder & A_OAAT & B_OAAT \\
RTFOT aged binder & A_RTFOT & B_RTFOT \\
RTFOT + PAV aged binder & A_RTFOT + PAV & B_RTFOT + PAV \\
\hline
\end{tabular}




\subsection{Rheological Characterization}

The rheological characterization of the neat and aged asphalt binders (NAAT, OAAT, RTFOT, and PAV + RTFOT) was performed using a rheometer (Thermo Scientific HAAKE MARS II, Karlsruhe, Germany). The frequency sweep test was conducted from 10 to $82{ }^{\circ} \mathrm{C}$, with an increment of $6{ }^{\circ} \mathrm{C}$ in temperature.

At each tested temperature, the frequency was varied from 0.1 to $10.0 \mathrm{~Hz}$. For temperatures from 10 to $40^{\circ} \mathrm{C}$, the tests were run in parallel plate geometry with a diameter of $8 \mathrm{~mm}$ and sample height equal to $2 \mathrm{~mm}$. For higher temperatures $\left(40-82^{\circ} \mathrm{C}\right)$, a parallel plate with $25 \mathrm{~mm}$ diameter and sample height of $1 \mathrm{~mm}$ was used. The strain amplitude for the tests was limited to $0.01 \%$ to guarantee that asphalt binders were tested in the linear viscoelastic (LVE) domain.

The dynamic shear modulus $\left(\left|\mathrm{G}^{*}\right|\right)$ is equal to the ratio of the stress to the strain amplitude obtained from frequency sweep test results. The higher this parameter is, the higher is the resistance of the material to deformation under load. The phase angle $(\delta)$ is the lag between the shear stress and shear strain, and its value can vary from $0^{\circ}$ to $90^{\circ}$. The zero value indicates that the analyzed material is completely elastic, and the $90^{\circ}$ value is related to its complete viscous behavior [23,24].

The $\left|G^{*}\right|$ and $\delta$ master curves were constructed based on the time-temperature superposition principle (TTSP) at $25{ }^{\circ} \mathrm{C}$ reference temperature. The Williams-Landel-Ferry model [25] was used to obtain the time-temperature shift factors. Finally, the master curves were determined according to the generalized power-law model [26], which was based on the Christensen-Anderson-Marasteanu (CAM) model [27].

\subsection{Fatigue Resistance}

The linear amplitude sweep (LAS) test was considered to evaluate the fatigue damage resistance of asphalt binders at different aging levels. The test was carried out according to provisional standard AASHTO TP 101-14 [28]. The test consists of two steps: (i) The frequency sweep test is run to obtain the undamaged material property ( $\alpha$ parameter). In this step, a strain amplitude of $0.1 \%$ is applied while the frequency varies from 0.2 to $30 \mathrm{~Hz}$. (ii) The amplitude sweep test is carried out on the same sample used in the previous step. The sample is progressively submitted to a linear increase in the strain amplitude from $0 \%$ to $30 \%$, while the frequency is kept constant at $10 \mathrm{~Hz}$.

The analysis of the results was done under the principle of the viscoelastic continuous damage (VECD) theory, which is based on Schapery's work potential theory [29]. The calculation of the $\alpha$ parameter obtained from the results of the first step is done according to the VECD theory. The B parameter is equal to twice the $\alpha$ value. Based on the $\alpha$ parameter and the results obtained from the second step, it is possible to determine at any time, the damage accumulation due to the degeneration of the material integrity. The damage value in the failure is considered to calculate the A parameter. Based on the determined parameters A and B, the fatigue performance parameter (Nf) is calculated using Equation (1):

$$
\mathrm{N}_{\mathrm{f}}=\mathrm{A}\left(\gamma_{\max }\right)^{-\mathrm{B}}
$$

where $\mathrm{N}_{\mathrm{f}}$ is the number of cycles to failure and $\gamma_{\max }$ is the maximum expected binder strain for a given pavement structure. A and B parameters are determined based on VECD.

In this study, the tests were carried out for unaged and aged binders (NAAT, OAAT, RTFOT, and RTFOT + PAV) at $+20^{\circ} \mathrm{C}$. The adopted failure criterion was the maximum value of the shear stress supported by the material during the amplitude sweep test. The fatigue behavior of the asphalt binder was determined using the spreadsheet provided by the Modified Asphalt Research Center (MARC) of the University of Wisconsin-Madison [30].

\subsection{Fourier-Transform Infrared (FTIR) Spectroscopy}

The spectra were recorded using an Attenuated Total Reflectance (ATR) FTIR spectrometer equipped with diamond crystal (Bruker Optics Inc, Model Alpha II, Ettlingen, Germany). Each spectrum 
was scanned 24 times at a resolution of $4 \mathrm{~cm}^{-1}$ and recorded in a range from 4000 to $600 \mathrm{~cm}^{-1}$. The test was conducted two times for each binder at all aging states (unaged, NAAT, OAAT, RTFOT and RTFOT + PAV aged).

The ATR-FTIR principle considered to obtain a spectrum is briefly described in the following sentences. When the infrared radiation hits the ATR crystal (material with high refractive index) at an angle of incidence greater than the critical angle, the beam undergoes total internal reflection. In this circumstance, an evanescent wave is created that extends beyond the surface of the crystal and penetrates a few micrometers into the sample adhered to the crystal. Various functional groups within the material can interact with the evanescent wave (change of dipole momentum), resulting in the adsorption of the infrared radiation at a specific wavelength. Finally, the resultant attenuated radiation is directed to the detector and converted via Fourier-transformation into the respective spectrum. The absorption spectrum shows the absorbed intensity of infrared radiation as a function of wavenumbers [31-33]. Certain functional groups exhibit characteristic absorptions of infrared radiation [34].

The spectrum can be analyzed to identify the structure of chemical compounds presented on the material. The oxidative aging of asphalt binders is usually evaluated based on the regions of absorbance peaks around 1030 and $1700 \mathrm{~cm}^{-1}$. Those band regions are related to the sulfoxide and carbonyl functional groups, respectively [16,35-42].

The evaluation of the oxygen uptake during the asphalt binder aging was based on the carbonyl and the sulfoxide indices. Both indices were determined according to the integration method considering the normalized spectrum (at band $2919 \mathrm{~cm}^{-1}$ ) and the absolute baseline. Further details of the calculation method used are given in [43]. Carbonyl and sulfoxide indices were calculated according to Equation (2) and Equation (3), respectively, as follows:

$$
\begin{aligned}
I_{C O} & =\frac{\text { Area around } 1700 \mathrm{~cm}^{-1}}{\text { Area around } 1460 \mathrm{~cm}^{-1}} \\
I_{S O} & =\frac{\text { Area around } 1030 \mathrm{~cm}^{-1}}{\text { Area around } 1460 \mathrm{~cm}^{-1}} .
\end{aligned}
$$

The wavenumbers integration limits considered for the calculation of the carbonyl index and sulfoxide index are given in Table 3:

Table 3. Carbonyl and sulfoxide indices integration limits.

\begin{tabular}{ccc}
\hline Structural Group & Upper Wave Number Limit $\mathbf{( c m}^{-\mathbf{1})}$ & Lower Wave Number Limit $\mathbf{( \mathbf { c m } ^ { - 1 } )}$ \\
\hline Carbonyl & 1755 & 1640 \\
Sulfoxide & 1060 & 984 \\
Reference (aliphatic) & 1525 & 1355 \\
\hline
\end{tabular}

\subsection{SARA Fractionation}

To investigate their chemical composition, asphalt binders are fractionated considering the principles of solubility and polarity. The separation of the asphalt binder into fractions aims to facilitate the assessment of the chemical changes that the material undergoes due to aging [44]. The acronym SARA (Saturates, Aromatics, Resins, and Asphaltenes) is used to name each fraction of the asphalt binder. The polarity increases from saturates to asphaltenes.

In this study, the asphalt binder fractionation was carried out according to an adapted version of the SARA fractionation methodology developed by Sakib et al. [45], which is mainly divided into two steps. In the first step, the asphaltenes (n-heptane insoluble) are separated from maltenes (n-heptane soluble) by solvent precipitation followed by filtration. The following step consists of fractioning the maltenes into saturates, aromatics, and resins based on elution-adsorption chromatographic principles using solid-phase extraction (SPE). Comparing solid-phase extraction to conventional elution-adsorption 
chromatography, SPE provides clear cutoff points in the polarity gradient, while chromatography is run in a continuous gradient mode. Using SPE, a clear classification of different polarity groups is achieved, which is advantageous for further analysis. The main difference between the method proposed by Sakib et al. [45] and the method considered in this study is the procedure used to dry the solvent solutions. In the next paragraphs, the methodology adopted in this study is briefly described. Further details can be found at $[45,46]$.

For the separation of asphaltenes from maltenes, $400 \pm 40 \mathrm{mg}$ of asphalt binder was dissolved in $40 \mathrm{~mL}$ of n-heptane (nonpolar solvent), and the solution was stirred for $24 \pm 2 \mathrm{~h}$ at room temperature (Figure 2a). Then, $10 \mathrm{~mL}$ of stirred solution was poured into the syringe (with PTFE syringe filters of $0.2 \mu \mathrm{m}$ pore size attached at its tips) mounted on ports of a vacuum manifold. The manifold connected to a vacuum source was used to accelerate the filtration process (Figure $2 b$ ). Additionally, $5 \mathrm{~mL}$ of n-heptane was passed through the same syringe-filter assuring that all the maltene was dissolved. The solution with maltenes was collected in a preweighed glass vial placed in the manifold and positioned just below the port. The precipitated asphaltenes were retained in the filter. The filtering process was repeated three more times, consuming the entire stirred solution.

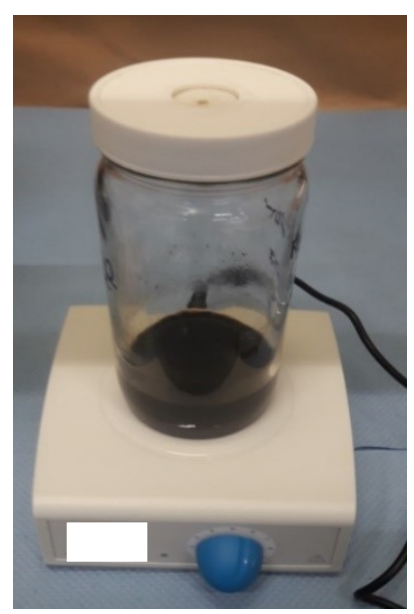

(a)

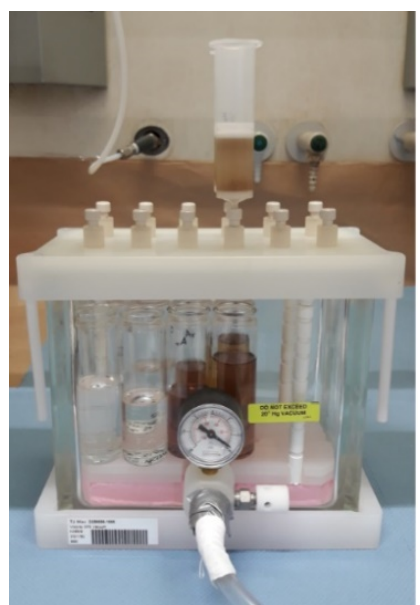

(c)

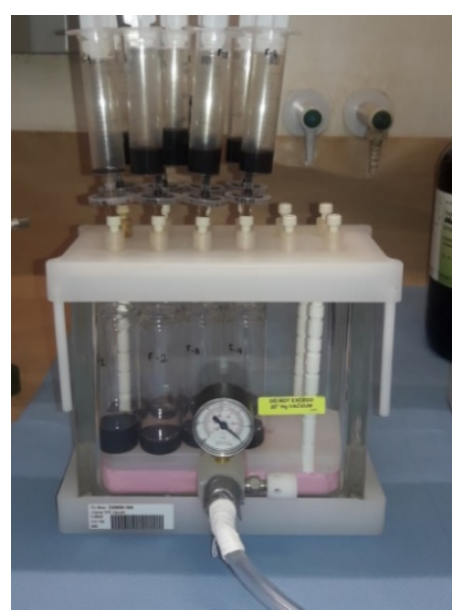

(b)

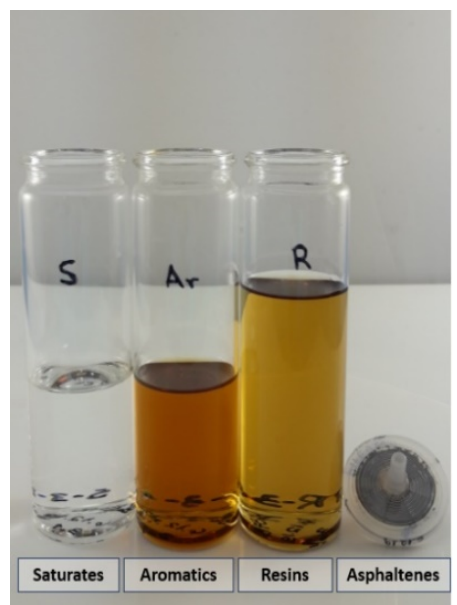

(d)

Figure 2. Saturates, Aromatics, Resins, and Asphaltenes (SARA) fractionation: (a) asphalt binder dissolution, (b) filtration of the solution, (c) maltene fractionation, and (d) SARA fractions. 
Two of the four obtained vials were dried until constant weight to determine the mass of maltene in each vial. For that, the vials were placed on a stirring hotplate at $135{ }^{\circ} \mathrm{C}$, and a flow of nitrogen was used to avoid oxidative aging and accelerate solvent evaporation. For safety reasons, the drying process was carried out inside a fume hood. The two vials were weighed, and the maltene content in the vials was measured gravimetrically.

The maltenes percentage in the asphalt binder was obtained based on the mass values of maltene and asphalt binder. The asphaltenes percentage was determined by subtracting the maltene percentage from $100 \%$. The maltene solution in the two remaining vials $(15 \mathrm{~mL}$ each) was diluted with $\mathrm{n}$-heptane to achieve approximately $3.33 \mathrm{mg} / \mathrm{mL}$ maltene/n-heptane $(w / v)$ ratio solution, which was used further for the maltene fractionation.

For the maltenes fractionation, SPE cartridge ( $5 \mathrm{~g}$ silica gel with $20 \mathrm{~mL}$ capacity and 60 A pore size) was mounted in one of the ports of the vacuum manifold. Then, $20 \mathrm{~mL}$ of $\mathrm{n}$-heptane was poured on the cartridge to prewash it. For the saturates collection, the cartridge was moved to the next port position and $15 \mathrm{~mL}$ of the diluted maltene solution was pushed through the cartridge followed by an extra $10 \mathrm{~mL}$ of $\mathrm{n}$-heptane. Then, the cartridge was moved again and $25 \mathrm{~mL}$ of $80: 20(v: v)$ toluene: $\mathrm{n}$-heptane solution was poured in the cartridge to gather the aromatics. Finally, the cartridge was moved to the last port position, $40 \mathrm{~mL}$ of 90:10 (v:v) dichloromethane and methanol solution was applied in the cartridge, to obtain the resins fraction (Figure 2c).

The vials with the eluted fractions were dried until constant weight according to the methodology used for drying the maltene solution, previously mentioned. Lastly, the vials were weighed to determine the saturates, aromatics, and resins fractions gravimetrically. In Figure $2 d$, the SARA fractions obtained after the asphalt binder fractionation are shown.

The n-heptane, toluene, dichloromethane, and methanol solvents used on the asphalt binder fractionation were high-performance liquid chromatography (HPLC) grade.

\section{Results and Discussion}

At least two replicates were run for all rheological (frequency sweep and LAS) and chemical (FTIR-ATR and SARA) characterization tests. In some cases, additional replicates were run to ensure that the coefficient of variation was within $10 \%$. The LAS, FTIR-ATR, and SARA results are given based on the average value.

\subsection{Master Curves}

Figure 3a-f show the dynamic shear modulus $\left(\left|G^{*}\right|\right)$ and phase angle $(\delta)$ master curves of binders $\mathrm{A}$ and $\mathrm{B}$ at different aging stages (unaged, NAAT, OAAT, RTFOT, and RTFOT + PAV) and at a reference temperature of $25^{\circ} \mathrm{C}$. Regardless of the asphalt binder aging state, for both binders, the $\left|G^{*}\right|$ values increased and the $\delta$ values decreased with the increment of reduced frequency.

For binders $A$ and B, it was observed that the $\left|G^{*}\right|$ and $\delta$ master curves of unaged state almost overlaid the curves of NAAT (Figure 3e), which indicates that the NAAT procedure did not significantly affect the stiffness and viscoelasticity of the asphalt binders. Based on this finding, it can be hypothesized that two events happened during the NAAT aging procedure: (i) absence of oxidation and loss of volatiles and (ii) no relevant thermal aging of the asphalt binders. The nitrogen atmosphere considered during the NAAT procedure may hinder the oxidation of the asphalt binders, even when the high temperature $\left(163^{\circ} \mathrm{C}\right)$ and extended exposure time $(4 \mathrm{~h})$ were considered.

The master curves $\left(\left|\mathrm{G}^{*}\right|\right.$ and $\left.\delta\right)$ at OAAT and RTFOT aging conditions were comparable (Figure 3f). This was observed for both binders (A and B). The similarity between the OAAT and RTFOT master curves indicated that the aging undergone by each asphalt binder during both aging procedures was very similar.

According to Table 4, both procedures (RTFOT and OAAT) considered the same temperature during the aging procedure $\left(163^{\circ} \mathrm{C}\right)$, however, each procedure considered specific values of the binder film thickness, procedure duration, and agitation mechanisms. It can be conjectured that the longer test 
duration considered in OAAT ( $240 \mathrm{~min}$ ) when compared to RTFOT (75 $\mathrm{min}$ ) was enough to compensate for the effect of higher thickness of the asphalt binder film and the absence of continuous movement during the OAAT aging procedure.

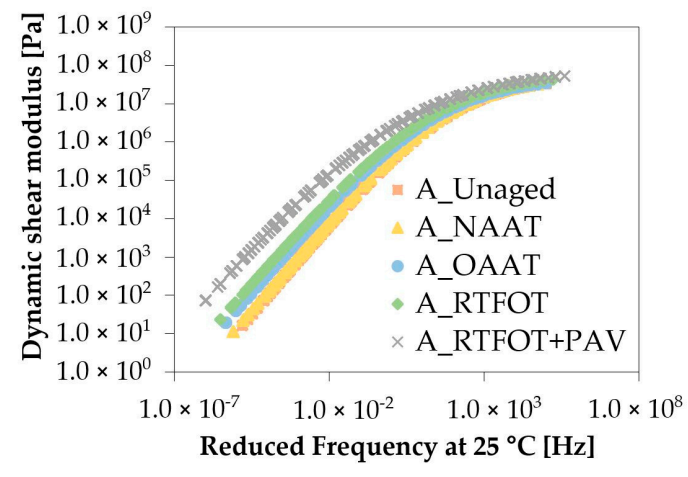

(a)

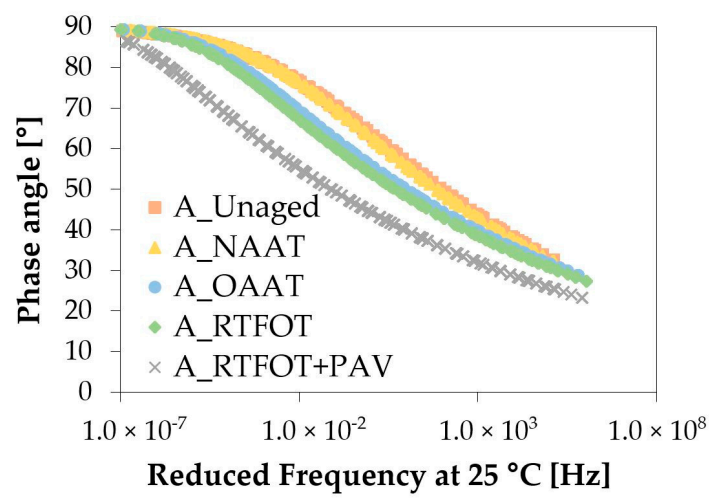

(c)

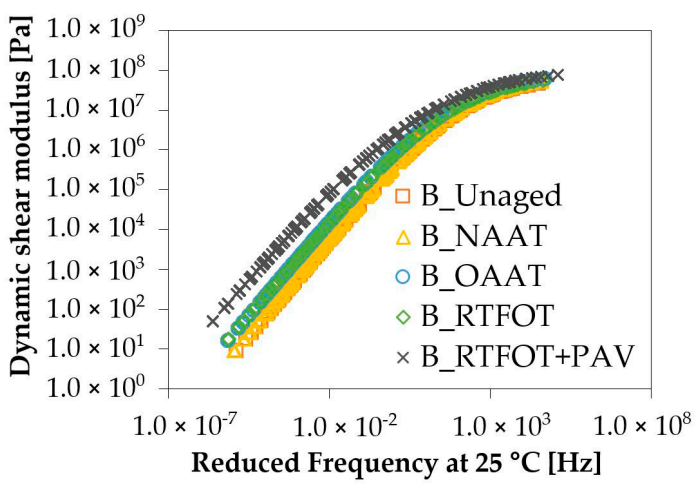

(b)

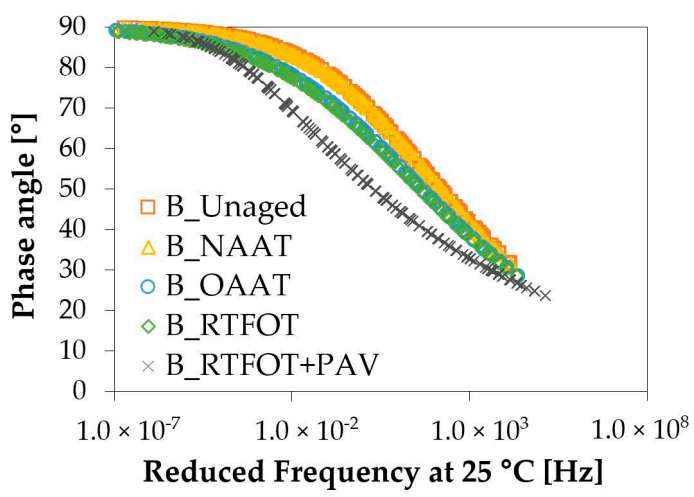

(d)

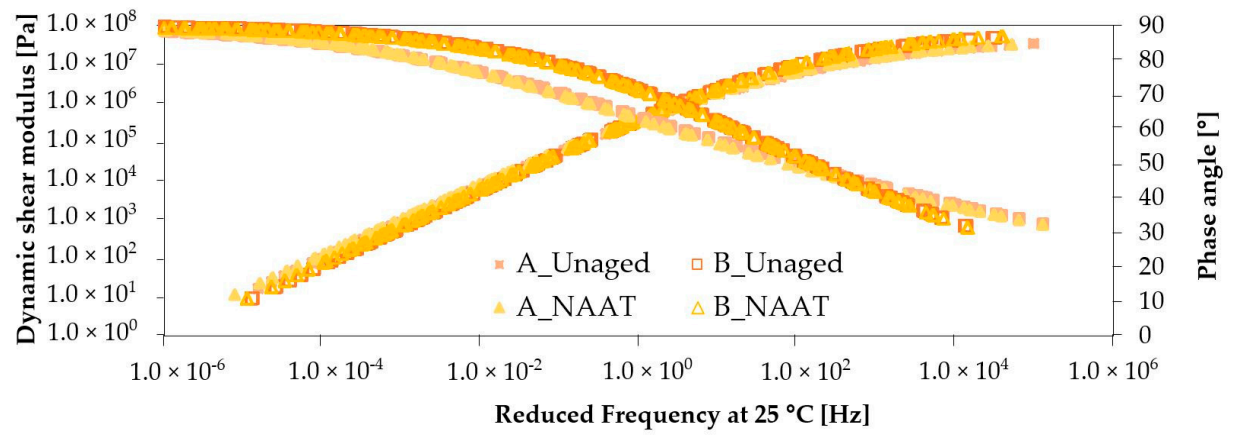

(e)

Figure 3. Cont. 


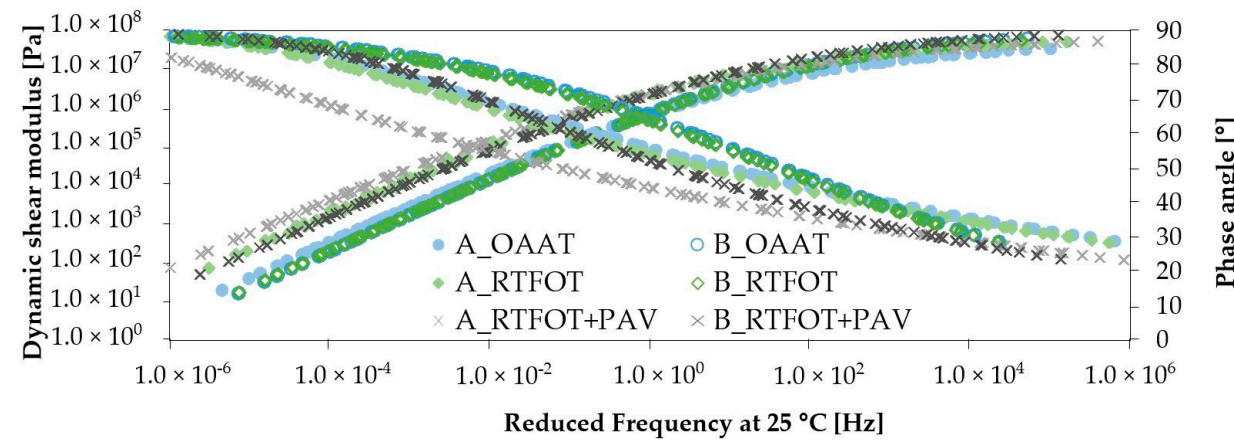

$(\mathbf{f})$

Figure 3. Master curves: (a) $\left|G^{*}\right|$ master curves of binder $A,\left(\right.$ b) $\left|G^{*}\right|$ master curves of binder $B$, (c) $\delta$ master curves of binder $A,(\mathbf{d}) \delta$ master curves of binder $B,(\mathbf{e})\left|G^{*}\right|$ and $\delta$ master curves of binder $A$ and B (at NAAT and Unaged conditions), and (f) $\left|G^{*}\right|$ and $\delta$ master curves of binder A and B (at OAAT, rolling thin-film oven test (RTFOT), and RTFOT + pressure aging vessel (PAV) conditions).

Table 4. Parameters of aging procedures (rolling thin-film oven test (RTFOT), ambient atmosphere oven aging test (OAAT), and nitrogen atmosphere oven aging test (NAAT)).

\begin{tabular}{cccc}
\hline Procedure & RTFOT & OAAT & NAAT \\
\hline Temperature $\left({ }^{\circ} \mathrm{C}\right)$ & 163 & 163 & 163 \\
Thin-film thickness $(\mathrm{mm})$ & 1.25 & 1.90 & 1.90 \\
Duration (minutes) & 75 & 240 & 240 \\
Aging atmosphere & Ambient air & Ambient air & Nitrogen \\
Sample is submitted to & Yes & No & No \\
continuous movement & & & \\
\hline
\end{tabular}

Moreover, the similarity between the OAAT and RTFOT master curves reinforces the hypothesis that the nitrogen considered in the NAAT aging procedure has inhibited the reaction of asphalt binders with oxygen, given that NAAT and OAAT considered similar aging procedures methodology (the only difference is that NAAT considers an inert atmosphere while OAAT considers an oxidative environment). Consequently, the inert atmosphere of nitrogen has prevented the binders from incorporating oxygen and subsequent physical hardening. In other words, the reaction of the asphalt binders with oxygen may be one of the main reasons for the stiffening of the material during OAAT and RTFOT aging procedures.

The RTFOT + PAV aging procedure led to an upward shift in $\left|G^{*}\right|$ master curves and downward shift in $\delta$ curves, in the overall frequency range (Figure 3f)). This is expected because LTA results in the increment of the stiffness and elastic performance of asphalt binders. Comparing the RTFOT + PAV phase angle master curve of both binders (Figure 3f), a different aging pattern is observed for each binder, indicating that LTA aging affected the rheology of the binder A and B in different ways. The increase in elasticity (decreasing in $\delta$ values) due to the LTA aging was more evidenced at low and intermediate frequency ranges showing that binder A may present higher resistance to fatigue and rutting when compared to binder $\mathrm{B}$.

To assess the mass change during NAAT and OAAT aging procedure, the mass change rate (MCR) was calculated in accordance with Equation (4). The MCR values regarding asphalt binders A and B are presented in Figure $4 a, b$, respectively.

$$
M C R=\left(\frac{\left(M_{1}-M_{0}\right)}{M_{0}}\right) \times 100,
$$

where $\mathrm{M}_{1}$ and $\mathrm{M}_{0}$ are the mass of the binders after and before aging, respectively. 


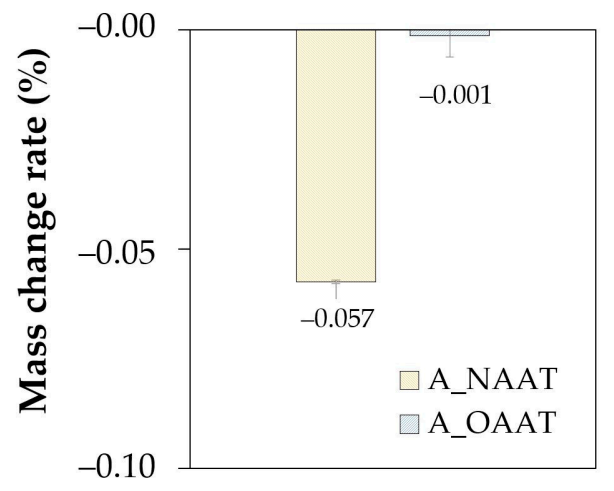

(a)

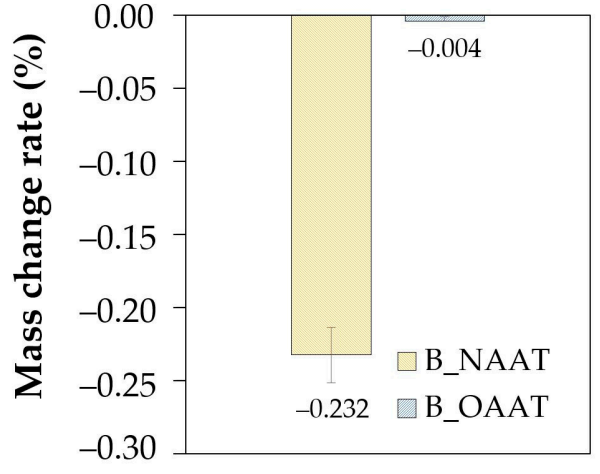

(b)

Figure 4. Mass change rate (after NAAT and OAAT aging procedure): (a) binder A; (b) binder B.

For both asphalt binders (A and B), it was observed a decrease in the mass of the asphalt binder after the NAAT. This finding indicates that volatile light components that are present in the fresh asphalt binders are evaporating solely due to the high temperatures $\left(163^{\circ} \mathrm{C}\right)$. On the other hand, the hypothesis that no relevant thermal aging of the asphalt binders seems to be reasonable since the rheological results showed that the volatilization of lighter compounds during NAAT did not affect the stiffness of the material.

In addition, the higher decrease in the mass of the asphalt binders after the NAAT when compared to the decrease after OAAT aging procedure indicates that the loss of mass due to the volatilization of lighter compounds was offset by the oxidation of the material.

In Figure 5, the inverse of the $\log$ crossover modulus $\left(1 / \log \left|\mathrm{Gc}^{*}\right|\right)$ for binder $A$ and binder $\mathrm{B}$ is shown. The cross modulus $\left|\mathrm{Gc}^{*}\right|$ is used to quantify the aging susceptibility of asphalt binders. It corresponds to the value of the modulus when the storage master curve and the loss modulus master curves cross each other. In other words, it is the value of modulus when the phase angle is equal to $45^{\circ}[47,48]$. In some studies, it was found an asphalt dependent correlation between $1 / \log \left|\mathrm{Gc}^{*}\right|$ and carbonyl content. It is expected that the higher this parameter, the greater the oxidation undergone by the material $[47,49]$.

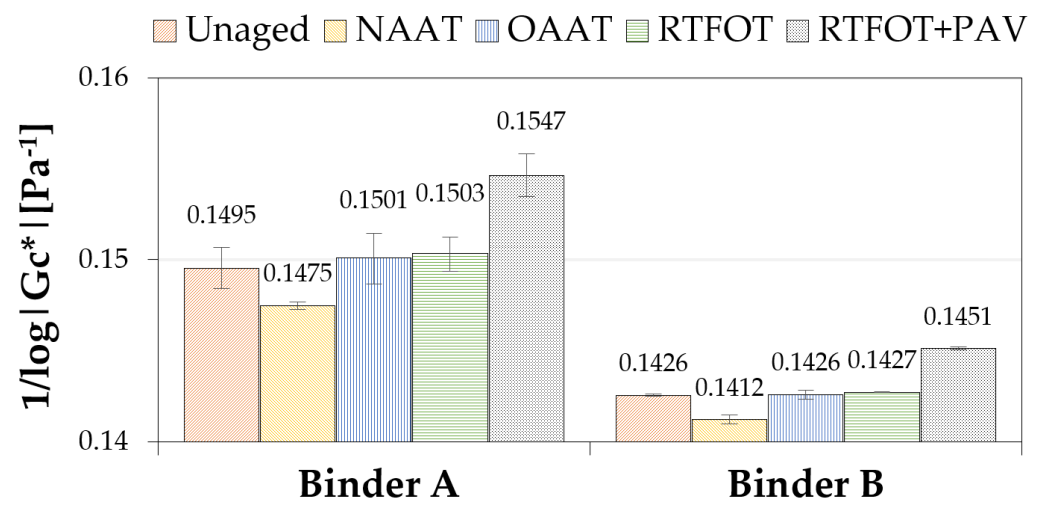

Figure 5. Values of the inverse of log crossover modulus for binders A and B.

According to Figure 5, the binders in the unaged, RTFOT, and OAAT conditions presented similar values of $1 / \log \left|G c^{*}\right|$, whereas the binders in the conditions NAAT and RTFOT + PAV presented the lowest and highest values of $1 / \log \left|G c^{*}\right|$, respectively. The results obtained suggest that $1 / \log \left|G c^{*}\right|$ may not be a suitable parameter to differentiate unaged from RTFOT aged samples. On the other hand, this parameter was effective in differentiating RTFOT + PAV from other binders. In addition, the lower 
values observed for NAAT binders when compared to unaged binders reinforce the hypothesis of the absence of oxidation and thermal aging during NAAT aging procedure.

\subsection{LAS Test}

Table 5 presents the average values of LAS parameters (A and B) obtained from the VECD analysis. The A parameter is correlated with the fatigue life of the material while the parameter $\mathrm{B}$ indicates the material sensitivity to an applied shear strain [50-55]. When the values of LAS parameters of binders $\mathrm{A}$ and $\mathrm{B}$ are compared for the same aging state, it was observed that binder A presented a higher absolute value of the parameters, which indicates its superior fatigue performance.

Table 5. Linear amplitude sweep (LAS) parameters.

\begin{tabular}{ccc}
\hline Binder & Parameter A & Parameter B \\
\hline A_Unaged & $5.7 \times 10^{5}$ & -2.91 \\
A_NAAT & $7.0 \times 10^{5}$ & -2.97 \\
A_RTFOT & $2.4 \times 10^{6}$ & -3.47 \\
A_OAAT & $1.9 \times 10^{6}$ & -3.36 \\
A_RTFOT + PAV & $1.1 \times 10^{7}$ & -4.35 \\
B_Unaged & $1.0 \times 10^{5}$ & -2.42 \\
B_NAAT & $9.4 \times 10^{4}$ & -2.39 \\
B_RTFOT & $2.7 \times 10^{5}$ & -2.76 \\
B_OAAT & $2.3 \times 10^{5}$ & -2.73 \\
B_RTFOT + PAV & $1.6 \times 10^{6}$ & -3.56 \\
\hline
\end{tabular}

Figure 6 shows the variation of the shear stress due to the progressive linear increase in shear strain during the amplitude sweep test. For the same aging state, binder B presented higher values of peak shear stress and lower values of shear strain at peak compared with binder A. Therefore, based on the obtained results, it can be hypothesized that binder $\mathrm{B}$ is more brittle and more prone to fatigue than binder A [44,56].

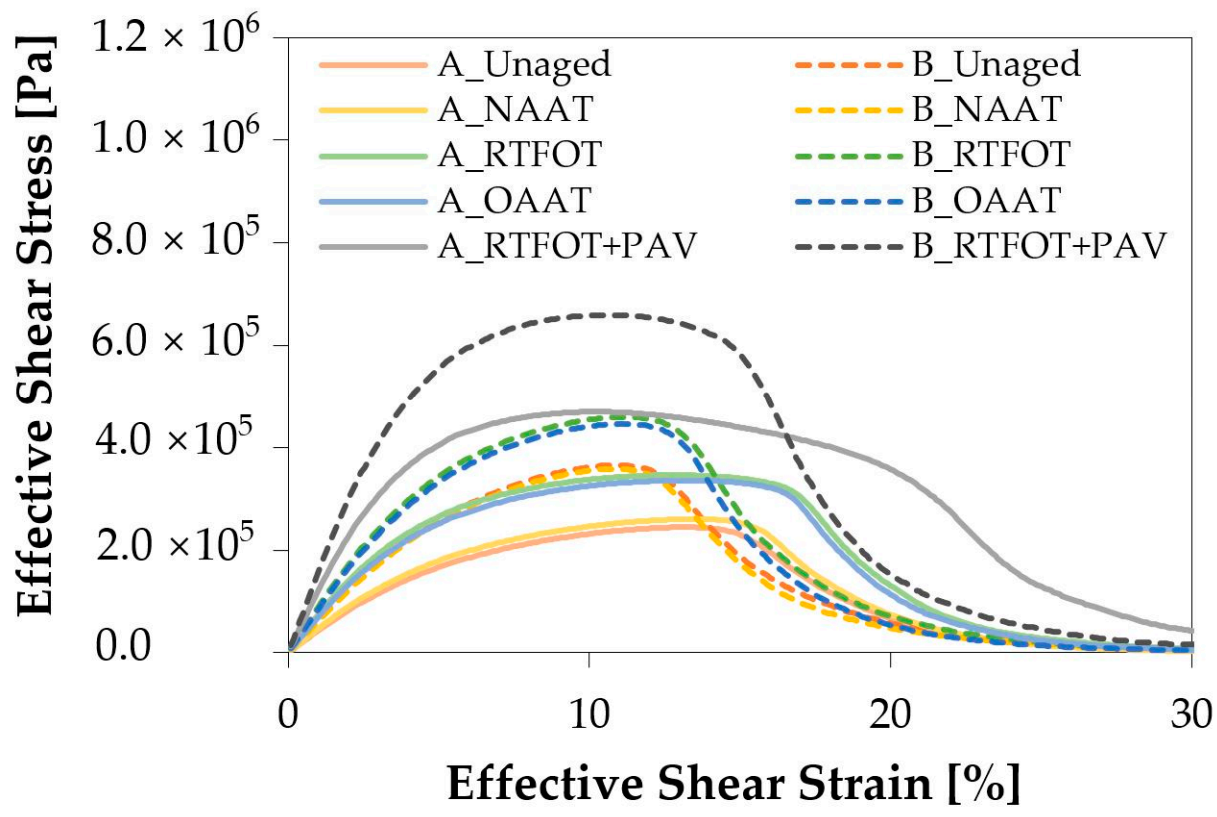

Figure 6. Shear stress $(\mathrm{Pa})$ versus shear strain $(\%)$. 
The fatigue curves of binder A and B are presented in Figure 7. For the same aging state, binder A presented higher fatigue life than binder B. This was expected based on the higher elasticity (Figure 3e,f) and the higher ductility (Figure 6) observed in binder A.

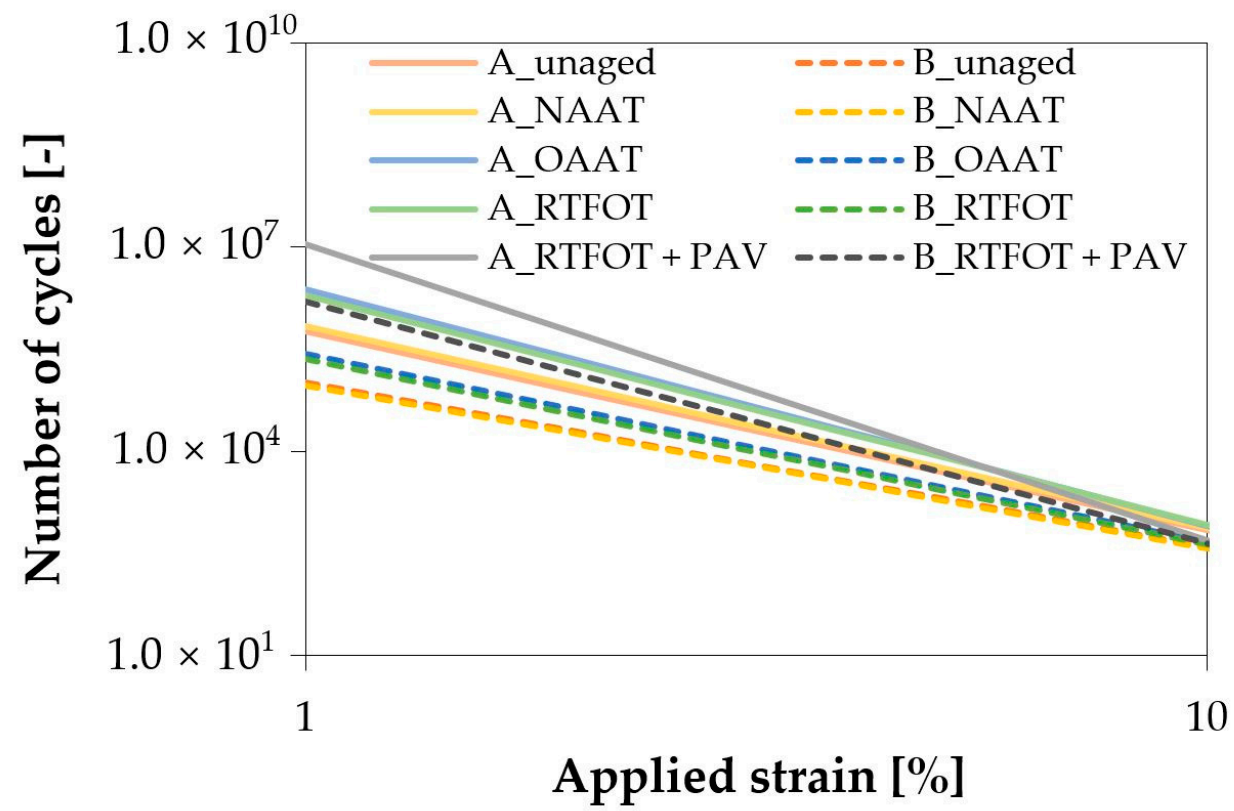

Figure 7. Fatigue life of binders A and B (at different aging conditions).

For both asphalt binders, it was observed that the fatigue curve of the unaged binder overlaps with the NAAT binder curve. The result was in accordance with the rheological analysis, which indicated that the inert atmosphere did not impact significantly the properties of the binders. Thus, no negative thermal aging effect can be observed on NAAT binders. In addition, the hypothesis that OAAT and RTFOT aging procedure age the asphalt binders in a similar way was also checked during the LAS test since similarity was observed between the fatigue behavior of the binders aged by OAAT and RTFOT procedure.

When high deformations were applied, it was observed that aging negatively affected the fatigue life of the material. However, at low levels of deformation (up to 10\%), it was found in this study as well as in other studies [57-59] that aging can be beneficial for the fatigue life of asphalt binders. Therefore, the prediction of pavement fatigue performance based on LAS results should be done cautiously, given that the study of Bennert and Maher [60] observed the fatigue behavior obtained through the LAS test was not in accordance with the fatigue cracking observed in the field.

\subsection{FTIR}

Figure $8 \mathrm{a}-\mathrm{c}$ displays the FTIR absorbance spectra for the binders considered in this study.

Usually, the effect of the aging is observed on band areas around the peaks at 1700, 1600, and $1030 \mathrm{~cm}^{-1}$, respectively, related to the carbonyl, aromatic, and sulfoxide chemical compounds. The increment of carbonyl and sulfoxide content is due to oxygen incorporation in the material [61-64]. The aromatization is correlated to the dehydrogenation of naphthenic rings, dimerization process, cyclization of alkyl chain, and aromatization of the perhydroaromatic ring $[17,65,66]$.

For both asphalt binders (A and B), the detailed visual analysis indicated that exposure to nitrogen during NAAT did not result in the formation of nitrogen-containing compounds. However, future chemical analyzes must be carried out to ensure that nitrogen did not react with asphalt binders during NAAT aging procedure. 


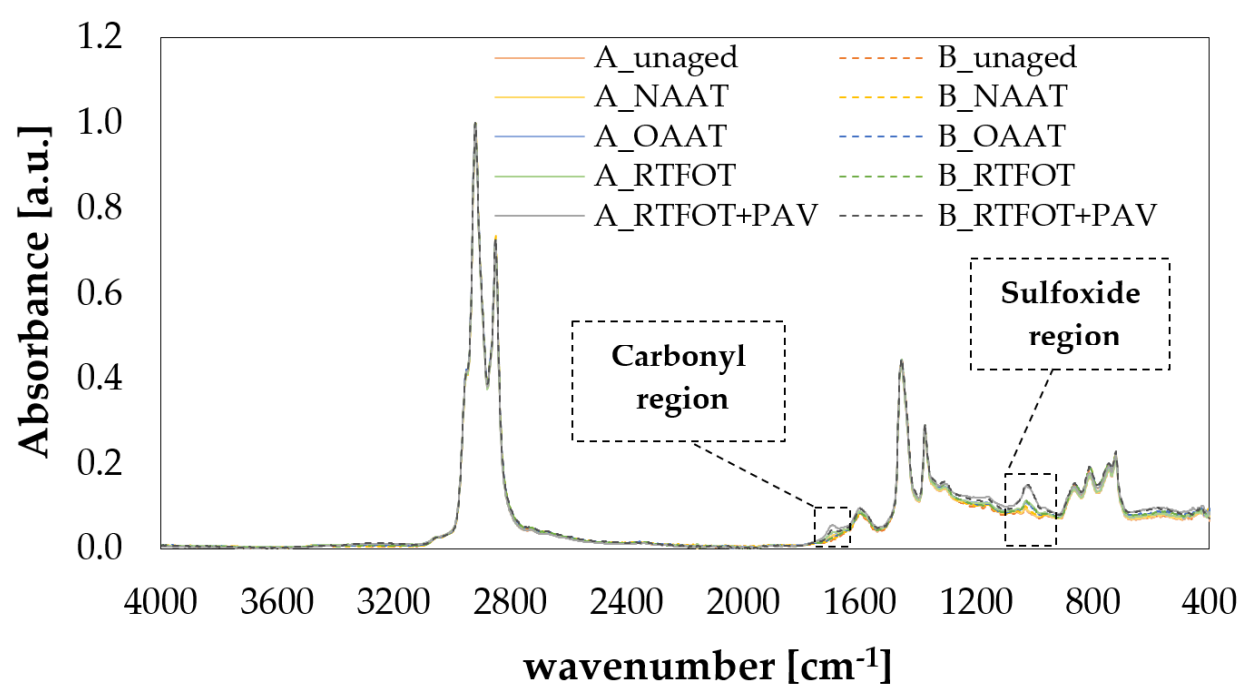

(a)

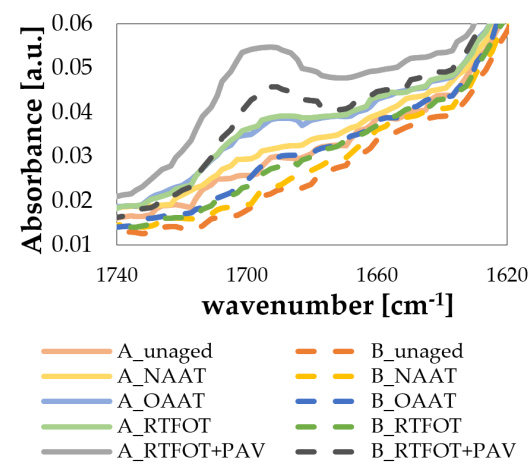

(b)

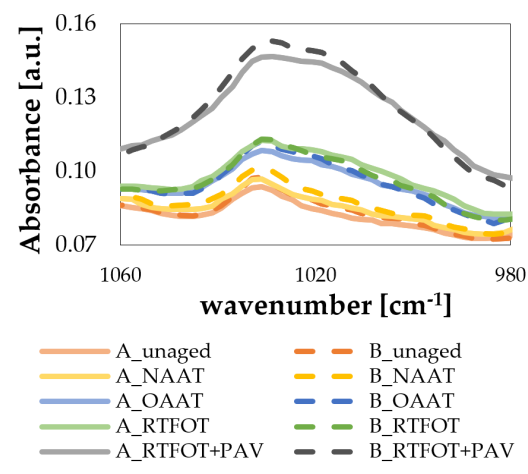

(c)

Figure 8. FTIR spectra: (a) complete spectra, (b) carbonyl region, and (c) sulfoxide region.

The summary of the main functional groups found in both binders is listed in Table 6. Both unaged asphalt binders (A and B) show bands assigned to aliphatic $\left(2919,2850,1456,1375\right.$, and $\left.721 \mathrm{~cm}^{-1}\right)$, aromatic $\left(1600,865,810\right.$, and $\left.745 \mathrm{~cm}^{-1}\right)$, and sulfoxide $\left(1030 \mathrm{~cm}^{-1}\right)$ functional groups. The carbonyl functional $\left(1700 \mathrm{~cm}^{-1}\right)$ was mainly formed after aging (OAAT, RTFOT, and RTFOT + PAV).

Table 6. Summary of the main bands and respective assignments.

\begin{tabular}{cc}
\hline Wavenumber $\left.\mathbf{( c m}^{-\mathbf{1}}\right)$ & Assignations \\
\hline 2919 & $\vee \mathrm{CH}_{2}$ (aliphatic) \\
2850 & $\vee \mathrm{CH}_{2}$ (aliphatic) \\
1693 & $\vee \mathrm{C}=\mathrm{O}$ (carbonyl) \\
1600 & $\vee \mathrm{C}=\mathrm{C}$ (aromatic) \\
1456 & $\delta \mathrm{CH}_{2}$ (aliphatic) \\
1375 & $\delta \mathrm{CH}_{3}$ (aliphatic) \\
1030 & $\vee \mathrm{S}=\mathrm{O}$ (sulfoxide) \\
865 & $\vee \mathrm{CH}$ (aromatic) \\
810 & $v \mathrm{CH}$ (aromatic) \\
745 & $v \mathrm{CH}$ (aromatic) \\
721 & $\mathrm{r} \mathrm{CH}$ (aliphatic) \\
\hline
\end{tabular}

Note: $v$-stretching; $\delta$-bending; $r$-rocking. 
In Figure 9, the values of carbonyl and sulfoxide indices are presented. The quantitative analysis showed that NAAT and unaged binders presented similar values of carbonyl and sulfoxide indices. The similarity between NAAT and unaged binders indices emphasizes the hypothesis that the inert atmosphere considered in the NAAT procedure was effective to diminish the oxidation of the asphalt binders (A and B) significantly and that no relevant thermal aging could be observed for these binder samples.

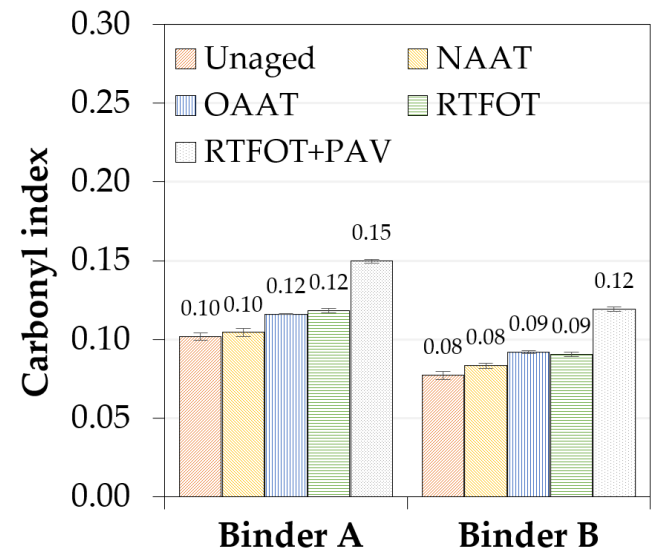

(a)

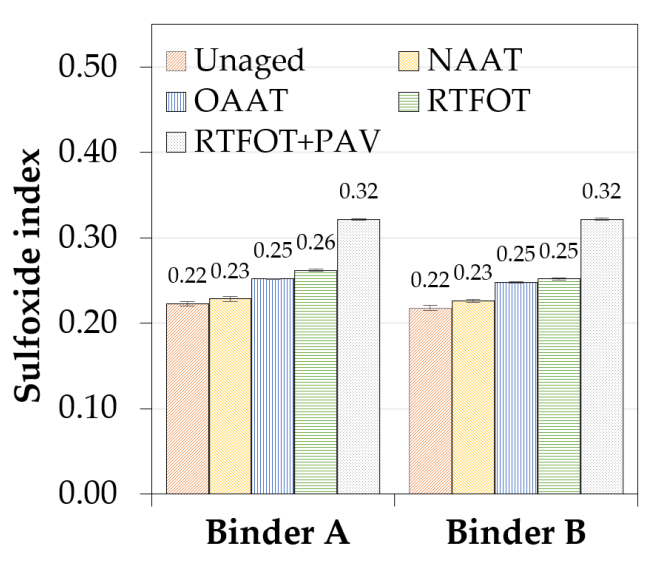

(b)

Figure 9. Aging indices: (a) carbonyl and (b) sulfoxides.

The carbonyl and sulfoxide indices of the OAAT and RTFOT binders were similar to one another and lower than the values obtained for RFTFOT + PAV binders. The possible explanations for the high values of carbonyl and sulfoxide indices observed for RTFOT + PAV binders are the use of a preaged RTFOT binder as a starting point and the application of high-pressure oxidation. The increase in pressure results in greater oxidation of the binder when the same temperature is considered [67].

In short, formation of both carbonyl and sulfoxide compounds was related to the rise of the oxidation severity brought by a specific aging procedure. Another important point to be highlighted is that binder A showed higher values of carbonyl indices than binder B, for the same aging state; this finding was in accordance with the drawn prediction based on $1 / \log \left|\mathrm{Gc}^{*}\right|$ parameter.

\subsection{SARA}

Asphalt binder aging alters their composition and chemical structure [68]. The change in the asphalt composition may result in a decrease in the amount of less polar compounds and increase in the amount of polar compounds. In Figure 10, the change in chemical composition caused by a specific type of aging procedure is shown. As expected, for both binders, the oxidative aging procedures (OAAT; RTFOT, and RTFOT + PAV) led to the decrease in aromatics and the increase in asphaltenes and resins; both components present high polarity. The change of saturates content was almost negligible. These findings are consistent with the results mentioned in other studies [69-71].

The higher stiffness of binder A when compared to binder B, especially after PAV aging procedure, should not be solely correlated to their asphaltene content [58,72]. Instead, the asphalt binder stiffness must be assessed from the total sum of the resins and asphaltenes fractions. The high polarity of asphaltenes and resins results in strong intermolecular attraction force between polar molecules. The higher the attraction between the molecules, higher is the stiffness of the material. Similarly, the increase in asphaltenes and resins during the aging of the asphalt binder favors the agglomeration of the molecules, which can cause hardening of the asphalt binders $[42,65,68,72-76]$. 


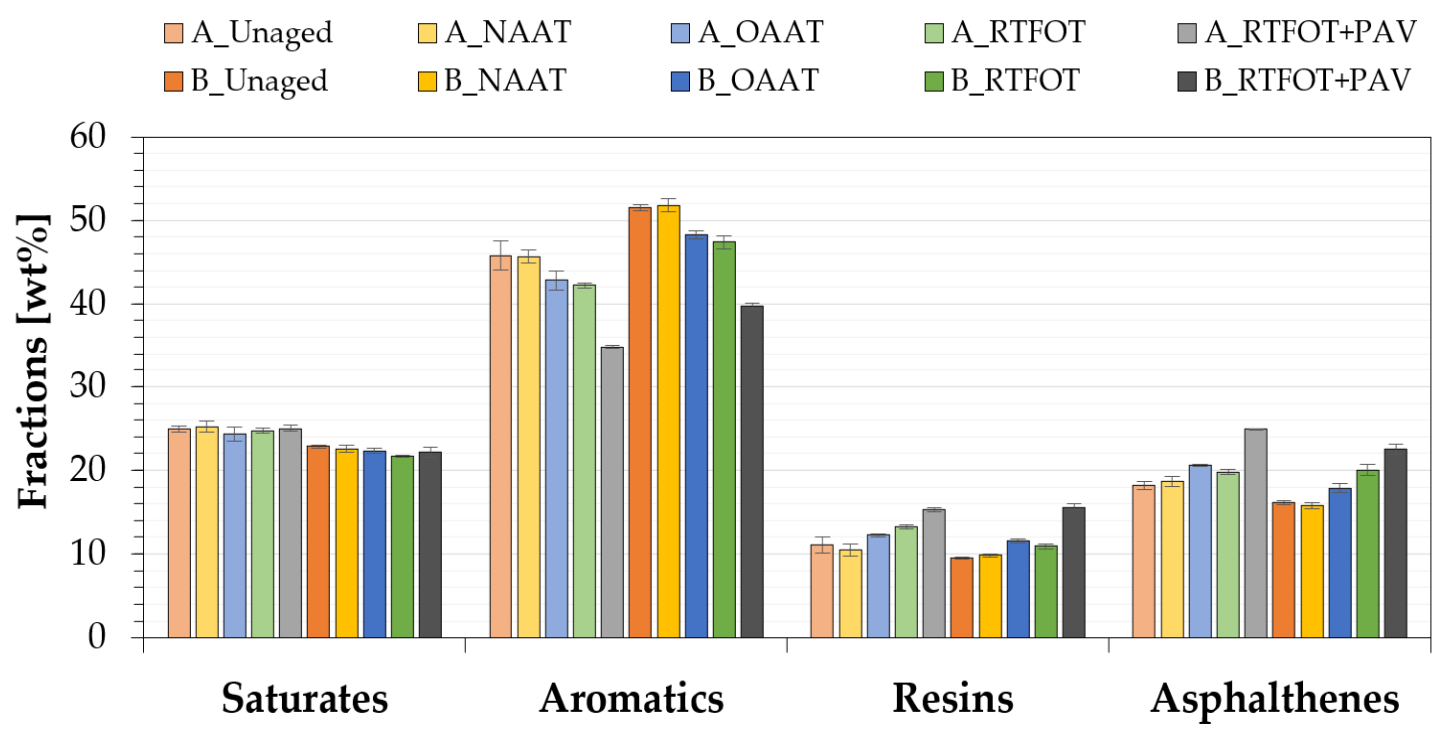

Figure 10. SARA fractions percentages at different aging states.

Additionally, the comparison between the fractions of the unaged binder to the RTFOT + PAV binder showed that both binders (A and B) presented a similar percentage variation for the aromatic and asphaltenes fractions due to the LTA. For both binders, the percentage of reduction in aromatics was close to $23 \%$, while the percentage of increase in asphaltenes was approximately $38 \%$. The same was not observed for resins fractions, indicating that aromatics may be the main asphaltenes-forming agents during the oxidation of asphalt binders, which has also been mentioned by Qin et al. [77].

For asphalt binders A and B, the values of each of the SARA fractions observed for the binders at unaged condition were very similar to those observed for binders at NAAT aged condition. More precisely, the percentage difference between unaged and NAAT binder was less than $6 \%$, for a given SARA fraction. The results are in accordance with the hypotheses made on the rheology and FTIR spectroscopy analysis regarding the effectiveness of the inert atmosphere (considered on NAAT aging procedure) on preventing changes in the material properties of both binders (A and B).

The micelle theory is usually considered to illustrate the colloidal molecular structure of asphalt binders. According to this theory, the micelles formed by the interaction of highly polar fractions (asphaltene and resins) are dispersed within a low polar maltene phase. The compatibility between the maltene and micelle is possible because the micelles are surrounded by a shell with a continuous polarity gradient. With oxidative aging, the chemical compositional of the shell is altered, which affects the stability of the material [2].

The Gaestel Index (Ic) is usually used to correlate the oxidative aging and the colloidal stability of the asphalt [78]. The Ic is defined as the ratio of the sum of percentage values of saturates and asphaltenes to the sum of percentage values of resins and aromatics [79]. The increase in the value of this index is usually correlated to the decrease in stability of the colloidal system $[80,81]$.

In Figure 11, the values of Ic different aging conditions are presented. For both asphalt binders (A and B), the values of Ic were close to 0.70 , which indicated that both asphalt binders have a gel-sol transition behavior [82]. However, it should be noted that in the present study, the SARA fractionation was based on the methodology developed by Sakib et al. (2019) using solid-phase extraction (discontinuous solvent gradient) instead of column chromatography (continuous solvent gradient) [45]. The pore size and the material of the filter used in this methodology lead to a higher yield of asphaltenes when compared to the values obtained by the ASTM D4124 standard. Therefore, it is expected that the Ic values calculated from the method proposed by Sakib et al. (2019) will be higher than those mentioned in other studies [45]. 


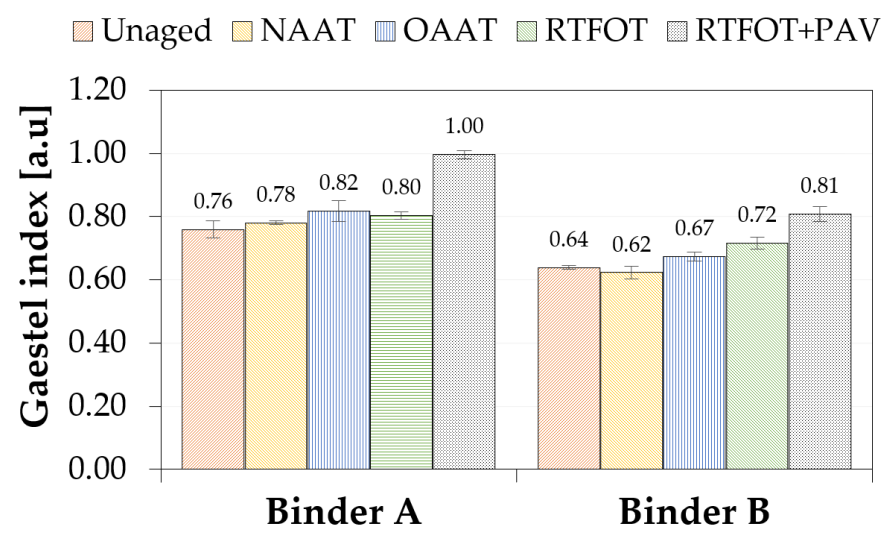

Figure 11. Gaestel Index.

In addition, it is noticed that binder B is more stable in terms of colloidal stability than binder A. This can be explained by its lower asphaltene content. Besides, the higher value of Ic for PAV asphalt binders indicates that the increase in asphaltene content negatively affects the stability of binder $\mathrm{A}$ and B.

\section{Conclusions}

In this study, the applicability of alternative laboratory aging methods was evaluated. The proposed methods aim at improving the assessment of the impacts of thermal and oxidative aging on the asphalt binder. The asphalt binders aged by the proposed methods and by RTFOT and PAV aging procedures were evaluated considering rheological and chemical characterization techniques. Based on the obtained test results, conclusions can be drawn as follows:

- The unaged binder and the binder aged by NAAT showed no significant difference in terms of the values of dynamic shear modulus, phase angle, fatigue life, carbonyl index, sulfoxide index, and SARA fractions. These observations were verified for both asphalt binders (A and B). The findings indicate that the proposed NAAT procedure was effective in minimizing the impact of oxidative aging (even when they were subjected to high temperatures and for a prolonged period) and consequently prevented the binders from stiffening. In other words, no relevant thermal aging could be observed for either of the binders after NAAT procedure.

- The asphalt binders aged by RTFOT and OAAT aging procedures showed similar rheological and chemical results.

- In general, RTFOT + PAV aged binder present the highest values of stiffness and elasticity. However, the increment in elasticity due to the LTA was more evident for binder A than binder B, indicating its better fatigue and rutting performance when compared to binder $\mathrm{B}$.

- Binder A presented a greater content of polar fractions (resins and asphaltenes) compared to binder $B$. The greater polarity results in a better association between polar molecules, thus higher stiffness when compared to binder B can be explained.

- The results of the rheological and chemical characterization showed that the NAAT aging procedure proposed in this study is effective to hinder the oxidation of the asphalt binders. This indicates that the NAAT method is a valuable tool to assess the individual effect that temperature and oxidation have on the aging of asphalt binders.

In summary, the results of the rheological and chemical characterization from samples aged by NAAT procedure showed that the impact of thermal aging (carried out in the absence of oxidation), i.e., mostly driven by volatilization, was negligible. Moreover, the results obtained for both asphalt binders $(\mathrm{A}$ and $\mathrm{B})$ indicate that oxidation is the main factor for the hardening of the asphalt binders. It is expected that the conclusions of this research will improve the understanding of the mechanisms that contribute to the aging of asphalt binders. 
Author Contributions: The authors confirm contribution to the paper as follow: proposed the idea and designed the experimental plan, I.G.d.N.C., B.H., H.G., and J.M.; carried out the experimental plan, I.G.d.N.C.; analyzed the data, I.G.d.N.C. and B.H.; writing-original draft preparation, I.G.d.N.C.; writing-review and editing, I.G.d.N.C., B.H., H.G., and J.M.; All authors have read and agreed to the published version of the manuscript.

Funding: This project has received funding from the European Union's Horizon 2020 research and innovation program under the Marie Sklodowska-Curie grant agreement No. 765057.

Acknowledgments: This study is part of the SAFERUP! Project, an innovative training network devoted to develop "safe, accessible, and urban pavements." The authors would like to thank Amit Bhasin (University of Texas at Austin) for his valuable comments and revision of the manuscript.

Conflicts of Interest: The authors declare no conflict of interest.

\section{References}

1. Butt, A.A.; Toller, S.; Birgisson, B. Life cycle assessment for the green procurement of roads: A way forward. J. Clean. Prod. 2015, 90, 163-170. [CrossRef]

2. Hofko, B.; Handle, F.; Eberhardsteiner, L.; Hospodka, M.; Blab, R.; Füssl, J.; Grothe, H.; Information, R. Alternative Approach toward the Aging of Asphalt Binder. Transp. Res. Rec. J. Transp. Res. Board 2015, 2505, 24-31. [CrossRef]

3. Trombulak, S.C.; Frissell, C.A. Review of Ecological Effects of Roads on Terrestrial and Aquatic Communities. Conserv. Biol. 2000, 14, 18-30. [CrossRef]

4. Bryce, J.; Brodie, S.; Parry, T.; Presti, D.L. A systematic assessment of road pavement sustainability through a review of rating tools. Resour. Conserv. Recycl. 2017, 120, 108-118. [CrossRef]

5. Soderlund, M.; Muench, S.T.; Willoughby, K.; Uhlmeyer, J.; Weston, J. Green Roads: A sustainability rating system for roadways. In Proceedings of the 87 TRB Annual Meeting, Washington, DC, USA, 13-17 January 2008.

6. Airey, G. State of the Art Report on Ageing Test Methods for Bituminous Pavement Materials. Int. J. Pavement Eng. 2003, 4, 165-176. [CrossRef]

7. Petersen, J.C. Chapter 14 Chemical Composition of Asphalt as Related to Asphalt Durability. In Developments in Petroleum Science; Elsevier: Amsterdam, The Netherlands, 2000; Volume 40, pp. 363-399.

8. Frolov, I.N.; Bashkirceva, N.Y.; Ziganshin, M.A.; Okhotnikova, E.S.; Firsin, A.A. The steric hardening and structuring of paraffinic hydrocarbons in bitumen. Pet. Sci. Technol. 2016, 34, 1675-1680. [CrossRef]

9. Little, D.N.; Allen, D.H.; Bhasin, A. Modeling and Design of Flexible Pavements and Materials; Springer: Berlin/Heidelberg, Germany, 2018.

10. Masson, J.-F.; Collins, P.; Polomark, G. Steric Hardening and the Ordering of Asphaltenes in Bitumen. Energy Fuels 2005, 19, 120-122. [CrossRef]

11. Read, J.; Whiteoak, D.; Hunter, R.N. The Shell Bitumen Handbook; Thomas Telford: London, UK, 2003.

12. Bell, C.A. Aging of Asphalt-Aggregate Systems; Summary Report; SHRP-A-305; Strategic Highway Research Program Publications: Washington, DC, USA, 1989.

13. Petersen, J.C.; Harnsberger, P.M. Asphalt Aging: Dual Oxidation Mechanism and Its Interrelationships with Asphalt Composition and Oxidative Age Hardening. Transp. Res. Rec. J. Transp. Res. Board 1998, 1638, 47-55. [CrossRef]

14. Petersen, J.C.; Glaser, R. Asphalt oxidation mechanisms and the role of oxidation products on age hardening revisited. Road Mater. Pavement Des. 2011, 12, 795-819. [CrossRef]

15. Petersen, J.; Harnsberger, P.; Robertson, R. Factors affecting the kinetics and mechanisms of asphalt oxidation and the relative effects of oxidation products on age hardening. Prepr. Pap. Am. Chem. Soc. Div. Fuel Chem. 1996, 41, 1232-1244.

16. Lu, X.; Isacsson, U. Effect of ageing on bitumen chemistry and rheology. Constr. Build. Mater. 2002, 16, 15-22. [CrossRef]

17. Petersen, J.C. A review of the fundamentals of asphalt oxidation: Chemical, physicochemical, physical property, and durability relationships. Transp. Res. Circ. 2009. [CrossRef]

18. Yu, J.; Feng, P.-C.; Zhang, H.-L.; Wu, S.-P. Effect of organo-montmorillonite on aging properties of asphalt. Constr. Build. Mater. 2009, 23, 2636-2640. [CrossRef]

19. CEN. EN 1426: Bitumen and Bituminous Binders-Determination of Needle Penetration; European Committee for Standardization: Brussels, Belgium, 2015. 
20. CEN. EN 1427: Bitumen and Bituminous Binders_Determination of the Softening Point_Ring and Ball Method; European Committee for Standardization: Brussels, Belgium, 2015.

21. CEN. EN 12607-1: Bitumen and Bituminous Binders-Determination of the Resistance to Hardening under Influence of Heat and Air-Part 1: RTFOT Method; European Committee for Standardization: Brussels, Belgium, 2014.

22. CEN. EN 14769: Bitumen and Bituminous Binders-Accelerated Long-Term Ageing Conditioning by a Pressure Ageing Vessel (PAV); European Committee for Standardization: Brussels, Belgium, 2012.

23. Kim, Y.R. Modeling of Asphalt Concrete; McGraw-Hill: New York, NY, USA, 2008.

24. Mallick, R.B.; El-Korchi, T. Pavement Engineering: Principles and Practice; CRC Press: Boca Raton, FL, USA, 2013.

25. Williams, M.L.; Landel, R.F.; Ferry, J.D. The Temperature Dependence of Relaxation Mechanisms in Amorphous Polymers and Other Glass-forming Liquids. J. Am. Chem. Soc. 1955, 77, 3701-3707. [CrossRef]

26. Huang, S.-C. Rubber Concentrations on Rheology of Aged Asphalt Binders. J. Mater. Civ. Eng. 2008, 20, $221-229$. [CrossRef]

27. Marasteanu, M.O.; Anderson, D.A. Improved model for bitumen rheological characterization. In Eurobitume Workshop on Performance Related Properties for Bituminous Binders; European Bitumen Association: Brussels, Belgium, 1999.

28. AASHTO. AASHTO TP 101-14: Standard Method of Test for Estimating Damage Tolerance of Asphalt Binders Using the Linear Amplitude Sweep; American Association of State and Highway Transportation Officials: Washington, DC, USA, 2014.

29. Schapery, R.A. Correspondence principles and a generalizedJ integral for large deformation and fracture analysis of viscoelastic media. Int. J. Fract. 1984, 25, 195-223. [CrossRef]

30. Qiu, Y.; Ding, H.; Rahman, A.; Wang, W. Damage characteristics of waste engine oil bottom rejuvenated asphalt binder in the non-linear range and its microstructure. Constr. Build. Mater. 2018, 174, 202-209. [CrossRef]

31. Salzer, R.; Siesler, H.W. Infrared and Raman Spectroscopic Imaging; John Wiley \& Sons: Hoboken, NJ, USA, 2014.

32. Stuart, B.H. Biological Applications of Infrared Spectroscopy; John Wiley \& Sons: Hoboken, NJ, USA, 1997.

33. Sun, D.-W. Infrared Spectroscopy for Food Quality Analysis and Control. Infrared Spectrosc. Food Qual. Anal. Control 2009. [CrossRef]

34. Larkin, P. Infrared and Raman Spectroscopy: Principles and Spectral Interpretation; Elsevier: Amsterdam, The Netherlands, 2017.

35. Bowers, B.F.; Huang, B.; Shu, X.; Miller, B.C. Investigation of Reclaimed Asphalt Pavement blending efficiency through GPC and FTIR. Constr. Build. Mater. 2014, 50, 517-523. [CrossRef]

36. Feng, Z.-G.; Wang, S.-J.; Bian, H.-J.; Guo, Q.-L.; Li, X. FTIR and rheology analysis of aging on different ultraviolet absorber modified bitumens. Constr. Build. Mater. 2016, 115, 48-53. [CrossRef]

37. Herrington, P.R. Thermal decomposition of asphalt sulfoxides. Fuel 1995, 74, 1232-1235. [CrossRef]

38. Hofko, B.; Porot, L.; Cannone, A.F.; Poulikakos, L.; Huber, L.; Lu, X.; Mollenhauer, K.; Grothe, H. FTIR spectral analysis of bituminous binders: Reproducibility and impact of ageing temperature. Mater. Struct. 2018, 51. [CrossRef]

39. Lamontagne, J.; Dumas, P.; Mouillet, V.; Kister, J. Comparison by Fourier transform infrared (FTIR) spectroscopy of different ageing techniques: Application to road bitumens. Fuel 2001, 80, 483-488. [CrossRef]

40. Lu, X.; Isacsson, U. Chemical and rheological evaluation of ageing properties of SBS polymer modified bitumens. Fuel 1998, 77, 961-972. [CrossRef]

41. Ongel, A.; Hugener, M. Impact of rejuvenators on aging properties of bitumen. Constr. Build. Mater. 2015, 94, 467-474. [CrossRef]

42. Zhang, F.; Yu, J.; Han, J. Effects of thermal oxidative ageing on dynamic viscosity, TG/DTG, DTA and FTIR of SBS- and SBS/sulfur-modified asphalts. Constr. Build. Mater. 2011, 25, 129-137. [CrossRef]

43. Hofko, B.; Alavi, M.Z.; Grothe, H.; Jones, D.; Harvey, J. Repeatability and sensitivity of FTIR ATR spectral analysis methods for bituminous binders. Mater. Struct. 2017, 50, 187. [CrossRef]

44. Huang, S.-C.; Grimes, W. Influence of Aging Temperature on Rheological and Chemical Properties of Asphalt Binders. Transp. Res. Rec. J. Transp. Res. Board 2010, 2179, 39-48. [CrossRef]

45. Sakib, N.; Bhasin, A. Measuring polarity-based distributions (SARA) of bitumen using simplified chromatographic techniques. Int. J. Pavement Eng. 2018, 20, 1371-1384. [CrossRef]

46. Sreeram, A.; Leng, Z.; Hajj, R.; Bhasin, A. Characterization of compatibility between aged and unaged binders in bituminous mixtures through an extended HSP model of solubility. Fuel 2019, 254, 115578. [CrossRef] 
47. Farrar, M.J.; Turner, T.F.; Planche, J.-P.; Schabron, J.F.; Harnsberger, P.M. Evolution of the crossover modulus with oxidative aging: Method to estimate change in viscoelastic properties of asphalt binder with time and depth on the road. Transp. Res. Rec. J. Transp. Res. Board 2013, 2370, 76-83. [CrossRef]

48. Huang, W.; Lin, P.; Tang, N.; Hu, J.; Xiao, F. Effect of crumb rubber degradation on components distribution and rheological properties of Terminal Blend rubberized asphalt binder. Constr. Build. Mater. 2017, 151, 897-906. [CrossRef]

49. Liu, F.; Wen, H. Prediction of Rheological and Damage Properties of Asphalt Binders that Result from Oxidative Aging. Transp. Res. Rec. J. Transp. Res. Board 2015, 2505, 92-98. [CrossRef]

50. Ameri, M.; Nowbakht, S.; Molayem, M.; Mirabimoghaddam, M.H. A study on fatigue modeling of hot mix asphalt mixtures based on the viscoelastic continuum damage properties of asphalt binder. Constr. Build. Mater. 2016, 106, 243-252. [CrossRef]

51. Ameri, M.; Seif, M.R.; Abbasi, M.; Khiavi, A.K. Viscoelastic fatigue resistance of asphalt binders modified with crumb rubber and styrene butadiene polymer. Pet. Sci. Technol. 2016, 35, 30-36. [CrossRef]

52. Ashish, P.K.; Singh, D.; Bohm, S. Evaluation of rutting, fatigue and moisture damage performance of nanoclay modified asphalt binder. Constr. Build. Mater. 2016, 113, 341-350. [CrossRef]

53. Elkashef, M.; Williams, R.C. Improving fatigue and low temperature performance of $100 \%$ RAP mixtures using a soybean-derived rejuvenator. Constr. Build. Mater. 2017, 151,345-352. [CrossRef]

54. Mirabimoghadam, M.H.; Goli, A.; Molayem, M.; Ameri, M. Experimental study on the effect of nanosized carbon particles on fatigue resistance of asphalt binders. Pet. Sci. Technol. 2016, 34, 971-975. [CrossRef]

55. Yu, J.; Ren, Z.; Yu, H.; Wang, D.; Svetlana, S.; Korolev, E.; Gao, Z.; Guo, F. Modification of Asphalt Rubber with Nanoclay towards Enhanced Storage Stability. Materials 2018, 11, 2093. [CrossRef]

56. Kataware, A.V.; Singh, D. Evaluation of intermediate temperature cracking performance of warm mix additive modified asphalt binders. Constr. Build. Mater. 2018, 184, 165-176. [CrossRef]

57. Elseifi, M.A.; Alvergue, A.; Mohammad, L.N.; Salari, S.; Aguiar-Moya, J.P.; Cooper, S.B. Rutting and Fatigue Behaviors of Shingle-Modified Asphalt Binders. J. Mater. Civ. Eng. 2016, 28, 04015113. [CrossRef]

58. Singh, D.; Sawant, D. Understanding effects of RAP on rheological performance and chemical composition of SBS modified binder using series of laboratory tests. Int. J. Pavement Res. Technol. 2016, 9, 178-189. [CrossRef]

59. Zhang, H.; Shen, K.; Xu, G.; Tong, J.; Wang, R.; Cai, D.; Chen, X. Fatigue resistance of aged asphalt binders: An investigation of different analytical methods in linear amplitude sweep test. Constr. Build. Mater. 2020, 241, 118099. [CrossRef]

60. Bennert, T.; Maher, A. Forensic study on the cracking of New Jersey's long-term pavement performance specific pavement study sections. Transp. Res. Record 2013, 2371, 74-86. [CrossRef]

61. Petersen, J.C. Quantitative functional group analysis of asphalts using differential infrared spectrometry and selective chemical reactions-theory and application. Transp. Res. Record 1986, 1096, 1-11.

62. Xiang, L.; Cheng, J.; Kang, S. Thermal oxidative aging mechanism of crumb rubber/SBS composite modified asphalt. Constr. Build. Mater. 2015, 75, 169-175. [CrossRef]

63. Yao, H.; Dai, Q.; You, Z. Fourier Transform Infrared Spectroscopy characterization of aging-related properties of original and nano-modified asphalt binders. Constr. Build. Mater. 2015, 101, 1078-1087. [CrossRef]

64. Zhang, R.; You, Z.; Wang, H.; Ye, M.; Yap, Y.K.; Si, C. The impact of bio-oil as rejuvenator for aged asphalt binder. Constr. Build. Mater. 2019, 196, 134-143. [CrossRef]

65. Branthaver, J.F.; Petersen, J.; Robertson, R.; Duvall, J.; Kim, S.; Harnsberger, P.; Mill, T.; Ensley, E.; Barbour, F.; Scharbron, J. Binder Characterization and Evaluation; SHRP-A-368; Chemistry, Strategic Highway Research Program Publications: Washington, DC, USA, 1993.

66. Michon, L.; Netzel, D.A.; Hanquet, B.; Martin, D.; Planche, J.-P. Carbon-13 molecular structure parameters of rtfot aged asphalts: Three proposed mechanisms for aromatization. Pet. Sci. Technol. 1999, 17, 369-381. [CrossRef]

67. Herrington, P.R.; Patrick, J.E.; Ball, G.F.A. Oxidation of Roading Asphalts. Ind. Eng. Chem. Res. 1994, 33, $2801-2809$. [CrossRef]

68. Huang, S.-C.; Zeng, M. Characterization of aging effect on rheological properties of asphalt-filler systems. Int. J. Pavement Eng. 2007, 8, 213-223. [CrossRef]

69. Dehouche, N.; Kaci, M.; Mokhtar, K.A. Influence of thermo-oxidative aging on chemical composition and physical properties of polymer modified bitumens. Constr. Build. Mater. 2012, 26, 350-356. [CrossRef] 
70. Isacsson, U.; Zeng, H. Relationships between bitumen chemistry and low temperature behaviour of asphalt. Constr. Build. Mater. 1997, 11, 83-91. [CrossRef]

71. Zhang, F.; Yu, J.; Wu, S. Effect of ageing on rheological properties of storage-stable SBS/sulfur-modified asphalts. J. Hazard. Mater. 2010, 182, 507-517. [CrossRef] [PubMed]

72. Michalica, P.; Kazatchkov, I.B.; Stastna, J.; Zanzotto, L. Relationship between chemical and rheological properties of two asphalts of different origins. Fuel 2008, 87, 3247-3253. [CrossRef]

73. Le Guern, M.; Chailleux, E.; Farcas, F.; Dreessen, S.; Mabille, I. Physico-chemical analysis of five hard bitumens: Identification of chemical species and molecular organization before and after artificial aging. Fuel 2010, 89, 3330-3339. [CrossRef]

74. Qu, X.; Liu, Q.; Guo, M.; Wang, D.; Oeser, M. Study on the effect of aging on physical properties of asphalt binder from a microscale perspective. Constr. Build. Mater. 2018, 187, 718-729. [CrossRef]

75. Xu, G.; Sha, A. Molecular dynamics study of oxidative aging effect on asphalt binder properties. Fuel 2017, 188, 1-10. [CrossRef]

76. Zadshir, M.; Hosseinnezhad, S.; Fini, E.H. Deagglomeration of oxidized asphaltenes as a measure of true rejuvenation for severely aged asphalt binder. Constr. Build. Mater. 2019, 209, 416-424. [CrossRef]

77. Qin, Q.; Schabron, J.F.; Boysen, R.B.; Farrar, M.J. Field aging effect on chemistry and rheology of asphalt binders and rheological predictions for field aging. Fuel 2014, 121, 86-94. [CrossRef]

78. Siddiqui, M.N.; Ali, M. Studies on the aging behavior of the Arabian asphalts. Fuel 1999, 78, $1005-1015$. [CrossRef]

79. Gaestel, C.; Smadja, R.; Lamminan, K. Contribution à la connaissance des propriétés des bitumes routiers. Rev. Gentile. Routes Aérodromes 1971, 466, 85-94.

80. Oliver, J.W. Changes in the chemical composition of Australian bitumens. Road Mater. Pavement Des. 2009, 10, 569-586. [CrossRef]

81. Zadshir, M.; Oldham, D.J.; Hosseinnezhad, S.; Fini, E.H. Investigating bio-rejuvenation mechanisms in asphalt binder via laboratory experiments and molecular dynamics simulation. Constr. Build. Mater. 2018, 190, 392-402. [CrossRef]

82. Lesueur, D. The colloidal structure of bitumen: Consequences on the rheology and on the mechanisms of bitumen modification. Adv. Colloid Interface Sci. 2009, 145, 42-82. [CrossRef] 